\title{
THE LOCAL APPLICATION OF ANTIGONOCOCCIC SERUM IN GONOBLENNORRHOEA AND OTHER EYE DISEASES
}

\author{
BY \\ DR. W. A. WILle \\ EMERITUS SENIOR PHYSICIAN OF THE EYE HOSPITAL OF \\ S. A., SEMARANG, JAVA
}

АвоUT ten years ago, when considering whether it would be possible to improve the therapy of gonoblennorrhoea, it occurred to me to try the local effect of antigonococcic serum. The idea at first sight seems somewhat strange, but in reality it is not irrational.

We know, that several of the therapeutic sera have a decided effect when injected parenterally inside the body. Whether this effect is due to the prevention of the growth of the microbes in the tissues, as believed by Parkinson, or to the neutralizing of the toxin, produced by the microbes, as believed by T. Madsen, or to them both-as I should think-is of small practical importance.

The question is only, whether the serum would have a similar effect, when applied locally on the conjunctiva.

This mode of application has hitherto been used only for the serum in hay fever, and as it seems, with some success.

I have here spoken about the sera which are commonly recognized as effective, but about the antigonococcic serum opinions are, as we know, divided. However, I found that there were reasons enough to make a fair trial, and I never regretted it, for the serum appears to be a very effective local remedy.

In a case of gonoblennorrhoea I found that the instillation of the serum, repeated twice or three times, has the same effect as one instillation of 2 per cent. sol. nitr. arg., but with this difference, that it causes no irritation or cauterisation, no pain, and it does not hurt the cornea. The application can thus take place in two or three séances, or more, during a day and a night. The instillation must be made in a very careful way. First the conjunctiva must be cautiously cleansed with boracic water, and afterwards dried in order to get the full effect of the remedy. In the ward in between the doctor's treatment the eyes must be kept clean as usual, and protargol 2 per cent. or electrargol can be instilled by the nurse every hour or every half hour, if necessary.

During the last five to six years all cases of gonoblennorrhoea have been treated in this way, and with especially good results. Still, I have not during this period had any malignant case under treatment, thus I cannot tell, how the result would be under such 
circumstances. In such cases it would perhaps be advisable to try hypodermic serum injections.

In the following I shall describe cases of gonoblennorrhoea treated with serum:

\section{Chinese boy-three weeks old-Semarang, Java}

During three days strong purulent secretion from the eyes.

The eyes are shut. The eyelids are swollen. The moment the eyelids are separated from each other, a liberal quantity of muco-pus is evacuated. Sample is taken for microscopy. Conjunctivae are strongly injected and swollen. Corneae are intact.

Conjunctivae are cautiously washed out with water, and 1 .per cent. cocaine is instilled. The eyelids are everted, they are cautiously swabbed with tampons, slightly moistened with boracic lotion, and then as much serum is instilled as is necessary to cover the whole surface of the conjunctiva. The eyelids are then kept everted for about a quarter of a minute in order to attain as strong an effect as possible. This cleansing and instillation is performed four times with 10 minutes' interval.

The parents refuse admission into the Eye Hospital.

For use at home is prescribed boracic water tampons and instillation of 2 per cent. protargol every hour.

The child was brought twice a day to the Eye Clinic, and was treated in the same way each time. The microscopic examination showed numerous gonococci. On the following day there was a very considerable improvement; after two days the child began to open the eyes, and after 5 days it was cured.

After having realised repeatedly the good effect of the serum in gonococcic infection, I began to try it in other eye diseases.

In the rather severe cases of conjunctivitis caused by Koch-Weeks bacilli it appeared to have a very good effect, and would shorten the course of the disease considerably, as shown in the following case:

\section{Dutch boy-fifteen days old}

The eye disease had begun 12 days previously. The eyes were continually kept closed. A good deal of muco-purulent secretion was present. The case had been treated with eye-drops, but without result.

The eyelids are stuck together by yellow crusts, and on opening the eyelids some muco-pus is evacuated. The conjunctiva is red and fornices tumid. The corneae are not affected.

Microscopy of the secretion showed numerous Koch-Weeks bacilli.

After thoroughgoing, but cautious cleansing of the edges of the lids and conjunctiva antigonococcus serum was three times instilled, with five minutes interval. Just before the instillation the eyes were 
softly touched with a well compressed boracic-water tampon, in order to prevent the serum being diluted by the tears. The eyes were kept partly open for a quarter of a minute, while the eyelids were softly moved in order to get the full effect of the serum. This treatment was given twice a day, while the child at home was treated with instillation with electrargol 4 times a day. In the course of two days the child began to open the eyes, and the secretion was very much diminished. In the course of 6 days the child was cured.

I have also used the serum combined with other treatment in several other eye diseases, as trachoma, conjunctivitis aestivalis and keratitis ramificata superficialis, and with good effect.

The antigonococcus serum which I have used through all these years I have got from Parke, Davis \& Co., Detroit, Michigan, U.S.A.

The firm informs me that the serum is obtained from the blood of horses that have been treated with gradually increasing doses of live cultures of gonococcus. The activity of the serum is controlled by agglutination tests, so that a uniformly potent product is assured. Each lot is subjected to rigid bacteriological and physiological tests, both while in bulk and also after enclosure in the final container. The serum is served out in glass bulbs, closed by a rubber cap, each containing two c.c. The bulb must be opened aseptically, and the pipette that has to be used must also be sterilized.

A handy way to keep the bulb is to wrap it up in a slip of wadding, and put it into an ointment pot of 15 c.c. The pipette must have a point $33 \mathrm{~mm}$. long, or the point must be bent so much that it can get to the last drops of serum, when the bulb is inclined. After the bulb has been opened, the serum will keep sound for one or two days in the tropics, and longer in a cooler climate.

Seeing that subcutaneous injection of serum sometimes causes severe serum reactions, we must consider the possibility that some local reaction could take place by the instillation of the serum. In fact this may happen, but very seldom, and in a very harmless way. After the patient has been treated with the serum one, two or three weeks without any reaction at all, suddenly the eyes become red after the instillation, and this may last one or two days or even longer. On a single occasion there was even a little chemosis. When the application of the serum ceases, these symptoms will quickly disappear, and the therapeutic effect is in these cases often especially strong. 